\title{
Diabetic lipemia associated with acute pancreatitis in a patient with type 2 diabetes
}

\author{
Daisuke Ogawa ${ }^{1,2 *}$, Jun Wada $^{1}$, Hirofumi Makino ${ }^{1}$ \\ ${ }^{1}$ Department of Medicine and Clinical Science, Okayama University Graduate School of Medicine, Dentistry and Pharmaceutical \\ Sciences, Okayama, Japan; \\ ${ }^{2}$ Department of Diabetic Nephropathy, Okayama University Graduate School of Medicine, Dentistry and Pharmaceutical Sciences, \\ Okayama, Japan; *Corresponding Author: daiogawa@md.okayama-u.ac.jp
}

Received 25 May 2011; revised 20 June 2011; accepted 28 June 2011.

\begin{abstract}
We report a 59-year-old man with diabetic lipemia associated with acute pancreatitis. The patient was being treated for type 2 diabetes, but his glycemic control was poor. Although his insulin secretory activity was preserved, acute pancreatitis developed because of hypertriglyceridemia and the patient had type $\mathrm{V}$ hyperlipidemia. After hospitalization, his hyperlipidemia and hyperglycemia improved in response to insulin infusion and hydration. It is well known that diabetic lipemia is caused by type 1 diabetes, but is rare in type 2 diabetes. Insulin resistance, as well as insulin deficiency, might play a role in the development of diabetic lipemia.
\end{abstract}

Keywords: Diabetic Lipemia; Type 2 Diabetes; Acute Pancreatitis

\section{INTRODUCTION}

Diabetic lipemia rarely occurs during uncontrolled hyperglycemia and is recognized by severe hypertriglyceridemia [1]. The clearance of very-low-density lipoprotein (VLDL) and chylomicrons from plasma is impaired because of decreased activity of lipoprotein lipase (LPL), due to severe insulin deficiency [2]. Diabetic lipemia is usually present in patients with poorly controlled type 1 diabetes [1], but is rarely reported in patients with type 2 diabetes. Here, we describe a case of acute pancreatitis caused by hypertriglyceridemia in a patient with type 2 diabetes.

\section{CASE REPORT}

A 59-year-old man was admitted to our hospital because of severe abdominal pain. The patient was diagnosed with type 2 diabetes ten years earlier, however, he has not been under medical care. Abdominal discomfort and appetite loss developed about one month before current admission, prompting the patient to seek medical advice at a local clinic. Physical examination showed abdominal guarding and was referred to our hospital for further examination and treatment. He did not take alcohol, and his level of triglyceride was within normal range one year before admission.

On admission, he was $160 \mathrm{~cm}$ tall and weighed $65 \mathrm{~kg}$ (BMI $25.4 \mathrm{~kg} / \mathrm{m}^{2}$ ). Arterial blood pressure was $156 / 70$ $\mathrm{mmHg}$ and the body temperature $36.8^{\circ} \mathrm{C}$. No xanthomatous lesion was noted in the eye lids or tendons. Abdominal muscle guarding and attenuated bowel sounds were found on physical examination. Generalized pancreatic edema was noted on abdominal computed tomography (CT), but there were no findings of common bile duct stone or gallstone. Laboratory data on admission showed elevation of pancreatic enzymes, hyperglycemia, and ketosis (Table 1), but arterial blood gas analysis showed no acidosis. Though the patient had been fasting for more than 24 hours, serum triglyceride as well as total cholesterol levels were markedly elevated (2595 $\mathrm{mg} / \mathrm{dl}$ and $850 \mathrm{mg} / \mathrm{dl}$, respectively) and direct examination of a serum sample after 24 hours at $4^{\circ} \mathrm{C}$ showed the presence of the creamy layer and turbid lower layers (Figure 1). Polyacrylamide-gel disc electrophoresis of serum lipoproteins revealed the presence of VLDL and a broad midband that contains intermediate-density lipoprotein (IDL) (Figure 2(a)). Apolipoproteins C-II, C-III, and $\mathrm{E}$ were markedly elevated. These findings were suggestive of type $\mathrm{V}$ hyperlipidemia. Urinary C-peptide was $97.2 \mu \mathrm{g} /$ day and anti-glutamic acid decarboxylase antibody was negative. There were no hematological abnormalities, and tests of renal functions were within normal limits. The final diagnosis was acute pancreatitis, diabetic ketosis, and diabetic lipemia.

Continuous administration of urinary trypsin inhibitor 
Table 1. Laboratory data on admission.

\begin{tabular}{cc}
\hline AST & $62 \mathrm{IU} / \mathrm{l}(8-40)$ \\
ALT & $63 \mathrm{IU} / \mathrm{l}(5-35)$ \\
$\gamma$-GTP & $389 \mathrm{IU} / \mathrm{l}(0-50)$ \\
Chorine esterase & $218 \mathrm{IU} / \mathrm{l}(180-440)$ \\
Amylase & $283 \mathrm{IU} / \mathrm{l}(43-155)$ \\
Lipase & $138 \mathrm{IU} / \mathrm{l}(7-52)$ \\
CRP & $18.6 \mathrm{mg} / \mathrm{dl}(<0.3)$ \\
PG & $358 \mathrm{mg} / \mathrm{dl}(70-109)$ \\
HbAlc & $8.0 \%(4.3-5.8)$ \\
Anti-GAD Ab & $<0.3 \mathrm{U} / \mathrm{ml}(<1.5)$ \\
Urinary C-peptide & $97.2 \mathrm{mg} / \mathrm{day}(39.2-167)$ \\
\hline Ketone body fraction & \\
Total ketone body & $723 \mathrm{mmol} / 1(<130)$ \\
Acetoacetate & $282 \mathrm{mmol} / 1(<55)$ \\
3-hydroxybutyrate & $441 \mathrm{mmol} / 1(<85)$ \\
Triglyceride & $2595 \mathrm{mg} / \mathrm{dl}(30-149)$ \\
Lipoprotein lipase & $53 \mathrm{ng} / \mathrm{dl}(164-284)$ \\
Total cholesterol & $850 \mathrm{mg} / \mathrm{dl}(130-219)$ \\
HDL cholesterol & $26 \mathrm{mg} / \mathrm{dl}(40-69)$ \\
LDL cholesterol & $91 \mathrm{mg} / \mathrm{dl}(80-139)$ \\
\hline Apolipoprotein & \\
A-I & $98 \mathrm{mg} / \mathrm{dl}(119-155)$ \\
A-II & $10.7 \mathrm{mg} / \mathrm{dl}(25.9-35.7)$ \\
B & $128 \mathrm{mg} / \mathrm{dl}(73-109)$ \\
C-II & $22.8 \mathrm{mg} / \mathrm{dl}(1.8-4.6)$ \\
C-III & $46.8 \mathrm{mg} / \mathrm{dl}(5.8-10.0)$ \\
E & $22.2 \mathrm{mg} / \mathrm{dl}(2.7-4.3)$
\end{tabular}

CRP: C-reactive protein, PG: plasma glucose, HbAlc: hemoglobin Alc, GAD: glutamic acid decarboxylase, HDL: high-density lipoprotein, LDL: low-density lipoprotein

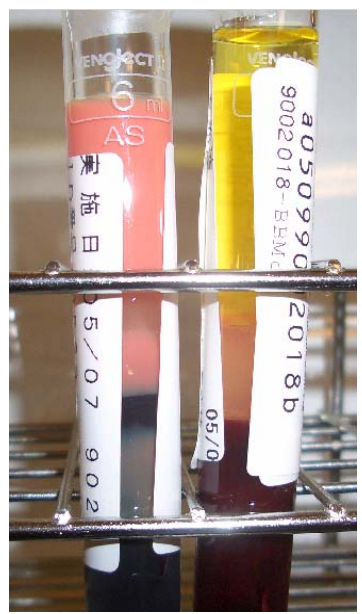

Figure 1. Appearance of serum on admission. The serum sample was allowed to stand for 24 hours at $4^{\circ} \mathrm{C}$. Left; the patient's serum, Right; control serum.

(100,000 U/day), nafamostat mesilate (20 mg/day), sulbactam sodium/cefoperazone sodium ( $2 \mathrm{~g} /$ day), and famotidine (40 mg/day) commenced for the treatment of acute pancreatitis. Continuous intravenous infusion of insulin $(1 \mathrm{U} / \mathrm{h})$, and saline were initiated for the treatment of hyperglycemia with ketosis. Epigastralgia diminished gradually and the levels of plasma glucose and C-reactive protein improved dramatically. The treatment of acute pancreatitis and insulin infusion was discontinued on the 9th hospital day. The level of triglyceride and total cholesterol improved to about $150 \mathrm{mg} / \mathrm{dl}$ and 200 $\mathrm{mg} / \mathrm{dl}$, respectively, after hospitalization without any lipid lowering agents. Fasting plasma glucose level also decreased to $100 \mathrm{mg} / \mathrm{dl}-110 \mathrm{mg} / \mathrm{dl}$ without oral diabetic agents or insulin. Electrophoresis of lipoproteins before discharge showed reduction of the midband (Figure 2(b)), indicating improvement of dyslipidemia. The patient had no abdominal pain and was discharged on the 27 th hospital day.

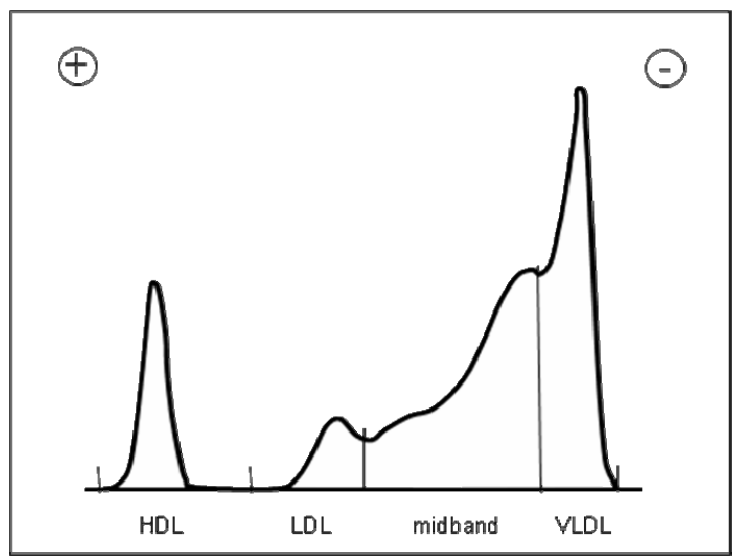

(a)

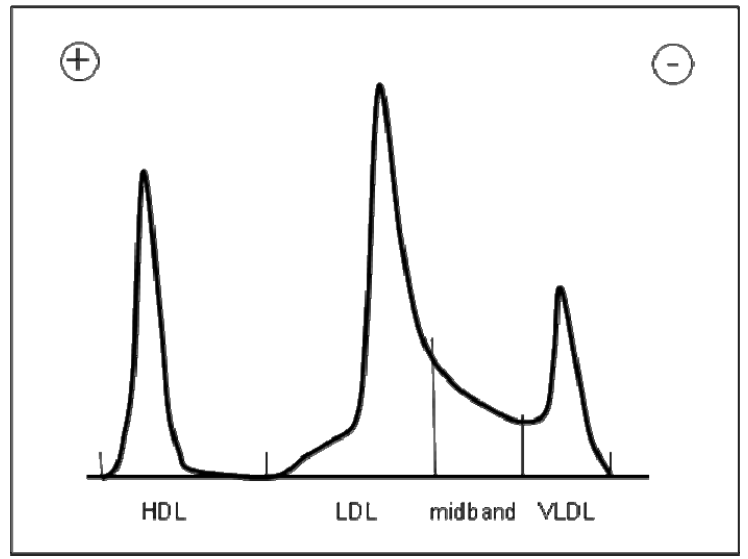

(b)

Figure 2. Polyacrylamide-gel disc electrophoresis of serum lipoproteins on (a) admission and (b) at discharge. Note the presence of very-low-density lipoprotein (VLDL) and a broad midband containing the intermediate-density lipoprotein (IDL) at admission and the associated reductions at discharge indicating improvement of dyslipidemia. HDL: high-density lipoprotein, LDL: low-density lipoprotein. 


\section{DISCUSSION}

This report described a patient with acute pancreatitis and diabetic lipemia during the course of type 2 diabetes. Diabetic lipemia rarely occurs in poorly controlled type 1 diabetic patients [1] and is caused by abnormal metabolism of the triglyceride-rich lipoprotein associated with insulin deficiency, which reduces LPL activity and causes disturbed clearance of chylomicrons and VLDL from plasma [2,3]. Family history reveals no evidence of familial lipoprotein lipase defect, and his serum triglyceride was within normal range from childhood. His triglyceride level was extremely high and lipoprotein lipase was low level on admission, but hypertriglyceridemia was promptly improved after the initiation of treatment. The pattern of polyacrylamide-gel disc electrophoresis of serum lipoproteins was also changed associated with the improvement of hypertriglyceridemia. In our case, excessive food intake and no treatment for diabetes might have caused marked insulin resistance as well as transient insulin deficiency and these factors resulted in diabetic lipidemia even in a patient with type 2 diabetes.

Hypertriglyceridemia is a rare cause of acute pancreatitis and accounts for only $1 \%-4 \%$ of the etiologies of acute pancreatitis [4]. In our case, hypertriglyceridemia might have caused acute pancreatitis because he did not take any alcohol and he did not have gallstone or common bile duct stone. The pathogenic relationship among acute pancreatitis, hypertriglyceridemia and diabetes is complex and not fully understood. In previous reports, acute pancreatitis associated with diabetes was usually encountered in the setting of diabetic ketoacidosis (DKA) [5-8]. Intriguingly, acute pancreatitis was associated with severe hypertriglyceridemia instead of DKA in our case. The mechanism is not clear, but, to our knowledge, hyperlipidemic pancreatitis has not been reported previously in a patient with type 2 diabetes without DKA. We speculate the mechanism by which severe hypertriglyceridemia induced acute pancreatitis by activating digestive enzymes in the pancreas.
In conclusion, we demonstrated that diabetic lipemia is a possible cause of acute pancreatitis even in a patient with type 2 diabetes and physicians should be aware that diabetic lipemia can cause acute abdomen in type 2 diabetic patients.

\section{ACKNOWLEDGEMENTS}

The authors declare no conflict of interest. Informed consent was obtained from the patient for publication of this case report.

\section{REFERENCES}

[1] Bagdade, J.D., Porte, D. Jr. and Bierman, E.L. (1967) Diabetic lipemia. A form of acquired fat-induced lipemia. The New England Journal of Medicine, 276, 427-433. doi:10.1056/NEJM196702232760802

[2] Howard, B.V. (1987) Lipoprotein metabolism in diabetes mellitus. The Journal of Lipid Research, 28, 613-628.

[3] Chait, A., Robertson H.T. and Brunzell J.D. (1981) Chylomicronemia syndrome in diabetes mellitus. Diabetes Care, 4, 343-348. doi:10.2337/diacare.4.3.343

[4] Tsuang, W., Navaneethan U., Ruiz L., Palascak J.B. and Gelrud, A. (2009) Hypertriglyceridemic pancreatitis: Presentation and management. The American Journal of Gastroenterology, 104, 984-991. doi:10.1038/ajg.2009.27

[5] Winter, R.J., Herr, T.J., Stone, N.J. and Traisman, H.S. (1980) Diabetic lipemia in childhood diabetic ketoacidosis: A clue to coexisting acute pancreatitis. Diabetes Care, 3, 706-707.

[6] Nair, S., Yadav, D. and Pitchumoni, C.S. (2000) Association of diabetic ketoacidosis and acute pancreatitis: $\mathrm{Ob}-$ servations in 100 consecutive episodes of DKA. The American Journal of Gastroenterology, 95, 2795-2800. doi:10.1111/j.1572-0241.2000.03188.x

[7] Chen, J.L., Spinowitz, N. and Karwa, M. (2003) Hypertriglyceridemia, acute pancreatitis, and diabetic ketoacidosis possibly associated with mirtazapine therapy: A case report. Pharmacotherapy, 23, 940-944. doi:10.1592/phco.23.7.940.32725

[8] Haddad, N.G., Croffie, J.M. and Eugster, E.A. (2004) Pancreatic enzyme elevations in children with diabetic ketoacidosis. Journal of Pediatrics, 145, 122-124. doi:10.1016/j.jpeds.2004.03.050 